\title{
STRATEGI PROMOSI SHIROKUMA CAFE DI MASA PANDEMI
}

\section{SHIROKUMA CAFE PROMOTION STRATEGY DURING PANDEMIC}

\author{
Cynthia Frida Lestari ${ }^{1)}$, Sofiani ${ }^{2)}$ \\ 1) Program Pariwisata, Universitas Bunda Mulia \\ 2)Program Pariwisata, Universitas Bunda Mulia
}

Diterima 2021 / Disetujui 2021

\begin{abstract}
ABSTRACK
The COVID-19 pandemic caused a significant effect for many economic sectors, especially the food and beverage industry. Many companies in this field are forced for either temporary or permanent closure. This study was conducted to find out what kind of promotional strategies done by Shirokuma Cafe during the pandemic to attract customers. This qualitative research was done by collecting data by interviewing, observing, as well as documenting the data gathered from both the head office as well as employees of Shirokuma Cafe. This study shows that promotional activities carried out by Shirokuma Cafe during the pandemic are sales promotion, and advertising that utilizes social media, namely Instagram, as well as direct marketing using SMS and whatsapp inform customers about their latest on going promos. These promotional strategy activities are effective in increasing sales at Shirokuma Café. Promotional activities that are not used by Shirokuma Cafe are personal sales and public relations activities due to unsupportive circumstances and budget. Shirokuma Café's promotional strategies such as sales promotion, advertising, and direct marketing focus on social media. In order to attract customers, Shirokuma Cafe can often hold activities such as holding seminars, giveaways, and collaborating with food bloggers to introduce their products to the public.
\end{abstract}

Keywords: Promotion Strategy, Shirokuma Café, COVID-19 Pandemic, Qualitative

\begin{abstract}
ABSTRAK
Pandemi COVID-19 memberikan dampak yang signifikan ke berbagai sector pekonomi, terutama pada industry makanan dan minuman. Banyak perusahaan yang berada dalam bidang ini terpaksa melakukan penutupan baik secarasementara mau pun permanen. Penelitian ini dilakukan untuk mengetahui strategi kegiatan promosi apa saja yang diambil oleh pihak Shirokuma Cafe di masa pandemi untuk menarik pelanggan. Penelitian ini merupakan penelitian kualitatif dengan metode pengumpulan data berupa wawancara, observasi, dan dokumentasi dengan sumber data yang berasal dari head office serta pegawai Shirokuma Cafe. Penelitian ini menunjukkan bahwa kegiatan promosi yang dilakukan Shirokuma Cafe di masa pandemi adalah sales promotion, dan periklanan yang memanfaatkan media sosial yaitu Instagram, serta direct marketing menggunakan SMS dan whatsapp untuk menginformasikan pelanggan sehubung promo yang sedang berjalan. Kegiatan-kegiatan strategi promosi tersebut efektif meningkatkan penjualan di Shirokuma Café. Kegiatan promosi yang tidak digunakan Shirokuma Cafe adalah kegiatan penjualan perorangan dan public relation dikarenakan keadaan dan budget tidak mendukung. Strategi Promosi Shirokuma Cafe seperti sales promotion, periklanan, dan direct marketing berfokus di media sosial. Guna menarik pelanggan Shirokuma Cafe bisa sering kali menggelar kegiatan seperti mengadakan seminar, giveaway, dan berkolaborasi dengan foodblogger guna memperkenalkan produk mereka ke masyarakat.
\end{abstract}

Kata Kunci: Strategi Promosi, Shirokuma Café, Pandemi COVID-19, Kualitatif 


\section{PENDAHULUAN}

Strategi promosi atau yang dikenal dengan istilah bauran promosi, merupakan bagian dari strategi pemasaran di mana setiap pelaku usaha pernah melakukan kegiatan dalam pengaplikasian dan menjalankan strategi promosi untuk menarik para pelanggan. Tujuan dari bauran pemasaran adalah untuk memperkenalkan dan menginformasikan produk yang mereka miliki dengan tujuan untuk meningkatkan penjualan (Sitorus \& Utami, 2017), dengan perkembangan teknologi informasi yang makin berkembang menuntut para pelaku usaha memperhatikan strategi promosi agar dapat mencapai tujuan perusahaan. Bauran promosi ini terbagi menjadi 5 bagian yaitu periklanan (advertising), promosi penjualan (sales promotion), penjualan perorangan (personal selling), promosi langsung (direct marketing), dan public relation. Sejak pandemi COVID-19 mulai mulai mewabah di Indonesia, bisnis-bisnis yang ada di negara ini mengalami penurunan penjualan, kondisi ini memaksa para pengusaha untuk mengembangkan strategi pemasaran yang baik terutama, terutama strategi promosi, untuk menarik para pelanggan demi mempertahankan bisnis mereka ditengah persaingan yang makin ketat. Menurut Perhimpunan Hotel dan Restoran Indonesia (PHRI), pandemi ini juga menyebabkan tingginya jumlah hotel dan restoran yang mengalami penutupan. Salah satu bisnis kuliner yang bertahan di era pandemi ini ialah Shirokuma Café yang berdiri sejak tahun 2014, Selain menawarkan dessert, Shirokuma Cafe juga menawarkan makan dan minuman dengan menu andalan mereka yanng berbasis matcha. Di tahun 2019, Shirokuma Cafe telah memiliki 8 outlet, di mana 2 di antaranya berada di luar Jakarta.

*Korespondensi Penulis:

E-mail: sofiani@bundamulia.ac.id
Efek dari pandemi COVID-19 ini juga terlihat dari menurunnya penjualan Shirokuma Cafe sebesar 70-80\% dari kondisi normal yang menyebabkan mereka terpaksa menutup 6 outlet yang mereka miliki di Jakarta. Shirokuma Cafe melakukan strategi promosi untuk menarik perhatian pelanggan dengan menjalankan strategi ini Shirokuma Cafe berhasil meningkatkan penjualan mereka. Penjualan yang sebelumnya mengalami penurunan $70 \%-80 \%$ kini hanya mengalami penurunan sebesar 40\%-50\%, Meski demikian hal ini tidak sesuai target yang direncanakan yaitu 20\%. Oleh sebab itu Shirokuma Cafe perlu menimbangkan kembali strategi promosi mereka. Tujuan dari penelitian ini adalah untuk mengetahui strategi promosi yang digunakan Shirokuma Cafe untuk meningkatkan penjualan di masa pandemi. Bagaimana strategi promosi yang digunakan oleh Shirokuma Café untuk meningkatkan penjualan di masa pandem.

\section{METODE PENELITIAN}

\section{Objek Penelitian}

Objek dari penelitian ini adalah Shirokuma Cafe yang ada di provinsi DKI Jakarta yang akan diteliti seperti apa strategi promosi pada Shirokuma Cafe di masa pandemi yang di mana gunanya untuk mengetahui strategi promosi Shirokuma untuk tetap bertahan di era pandemi saat ini.

\section{Subjek Penelitian}

Menurut (Fitrah \& Luthfiyah, 2017) subjek penelitian adalah orang yang memberi informasi data yang diinginkan peneliti berkaitan dengan penelitian yang berkaitan dengan penelitian yang sedang dilaksanakan. Pada dasarnya subjek penelitian adalah yang akan dikenai kesimpulan hasil penelitian. Sumber data dari judul penelitian "Strategi Promosi Shirokuma Cafe di Masa Pandemi" adalah Ibu Victoria yang menjabat sebagai Head Office Shirokuma Cafe yang menjadi narasumber utama, dan Bapak Chandra yang menjabat sebagai pegawai Shirokuma Cafe yang menjadi narasumber pendukung. 


\section{Teknik Pengumpulan Data}

Menurut (Sugiyono, 2015) teknik pengumpulan data adalah langkah yang paling penting dalam melakukan suatu penelitian, dikarenakan tujuan tujuan utama dari penelitian adalah untuk mendapatkan data. Dapat disimpulkan bahwa teknik pengumpulan data merupakan cara yang digunakan para peneliti untuk memperoleh data yang diperlukan dari narasumber. Peneliti pada penelitian ini menggunakan teknik pengumpulan data berupa observasi, wawancara, dan dokumentasi. Teknik ini masuk ke dalam data primer dikarenakan jenis data yang diperoleh dengan melibatkan kontak atau komunikasi langsung antara peneliti dengan narasumber.

\section{a. Observasi}

Observasi dilakukan agar peneliti dapat mengamati, merasakan, dan memahami keadaan yang ada pada objek penelitian secara langsung untuk bisa mendapatkan informasi-informasi yang ada untuk menyempurnakan penelitian ini. Peneliti sebagai pengamat mengamati outlet-outlet Shirokuma Cafe yang ada di Jakarta selama masa pandemi seperti apa

keadaannya.

b. Wawancara

Wawancara akan dilakukan oleh peneliti pada tanggal 6 Mei 2021 di office milik Shirokuma Cafe yang berlokasi di Pantai Indah Kapuk. Menurut (Sugiyono, 2015) wawancara merupakan teknik pengumpulan data jika peneliti ingin melakukan suatu studi pendahuluan untuk bisa menemukan suatu permasalahan yang harus di teliti pada penelitian. Selain itu juga jika peneliti ingin mengetahui banyak hal dari responden lebih mendalam lagi.

c. Dokumentasi

Dalam penelitian ini peneliti mengumpulkan segala dokumen seperti hasil wawancara, data pengunjung Shirokuma Cafe, gambar-gambar suasana outlet dan kantor pusat Shirokuma Cafe. Menurut (Sugiyono, 2015) teknik dokumentasi digunakan untuk menjadi pelengkap dari metode observasi dan wawancara dalam penelitian kualitatif.

\section{Teknik Keabsahan Data}

Pada penelitian kualitatif, hal paling penting pada hasil data penelitian adalah bersifat valid, reliabel, objektif dan dapat dipercaya. Menurut (Sugiyono, 2015) validitas merupakan ketepatan yang terjadi di antara data yang ada pada objek penelitian dengan laporan peneliti itu sesuai. Apabila laporan peneliti tidak sesuai dengan apa yang terjadi di objek penelitian, maka data tersebut dinyatakan tidak valid. Teknik keabsahan data yang akan digunakan peneliti adalah uji kredibilitas data dengan metode tringulasi.

Menurut (Sugiyono, 2015) adalah teknik di mana untuk melakukan suatu pengujian kredibilitas. Dapat diartikan tringulasi sebagai teknik untuk melakukan pengecekan data dari berbagai sumber dengan berbagai cara, dan berbagai waktu.

Teknik tringulasi menurut (Sugiyono, 2015) terdapat 3 cara, yaitu:

1. Tringulasi sumber

Tringulasi sumber dilakukan untuk mengetahui kredibilitasnya dengan cara melakukan pengecekan data yang didapat melalui melakukan pertanyaan yang sama terhadap sumber-sumber yang berbeda. Datadata yang diperoleh dari beberapa sumber tidak bisa disama ratakan, tetapi di deskripsikan dan dikategorisasikan mana pandangan yang sama mana yang pandangannya berbeda. Kemudian, data-data yang di dapat akan dianalisis oleh peneliti untuk mendapatkan suatu kesimpulan.

2. Tringulasi teknik

Tringulasi teknik melakukan pengecekan data kepada sumber yang sama tetapi menggunakan teknik yang berbeda. Seperti misalnya data yang diperoleh dari wawancara, lalu dilakukan pengecekan dengan melakukan observasi atau dokumentasi.

\section{Tringulasi waktu}

Teknik tringulasi waktu merupakan teknik pengujian kredibilitas yang lebih memperhatikan perilaku dari narasumber pada waktu tertentu.

\section{HASIL DAN PEMBAHASAN}


Shirokuma Cafe merupakan salah satu usaha yang bergerak di bidang kuliner atau food and Beverage. Shirokuma Cafe sendiri memiliki 8 cabang yang berlokasi di Gandaria City, Kota Kasablanka, Grand Indonesia, PIK, Pondok Indah Mall, Mall Sumerecon Bekasi, AEON BSD, dan Margo City. Namun dikarenakan adanya pandemi COVID-19, hanya tersisa 2 cabang Shirokuma Cafe di Kota Kasablanka dan Gandaria City. Sementara, kantor pusat milik Shirokuma Cafe ini sendiri berlokasi di Ruko Gallery 8, Blok EK \& EL, JL. Pantai Indah Utara 2, Pantai Indah Kapuk, Jakarta yang tergabung di dalam Tanamera Coffee Roastery.

Shirokuma Cafe berdiri sejak tahun 2014 dan merupakan usaha yang didirikan oleh Michelle Widjaja. Awal mula didirikannya shirokuma cafe berasal dari ketertarikannya terhadap Matcha. Melihat adanya potensi untuk es krim soft cream a la Jepang, Michelle memutuskan untuk membuat kafe dessert di Indonesia. Nama Shirokuma diambil dari bahasa Jepang yang berarti 'beruang putih', sesuai dengan nama julukan yang dimilikinya ketika masih kecil. Visi \& Misi Shirokuma Cafe:

$\checkmark$ Act with Integrity Kami selalu melakukan hal yang benar, walaupun tidak ada satu orang pun yang melihat.

$\checkmark$ Customer Service Excellence Kami menciptakan pengalaman dan ingatan yang menyenangkan kepada seluruh customer.

$\checkmark$ Teamwork and Family Kami bekerja sama sebaik-baiknya untuk meraih pencapaian yang lebih besar lagi.

$\checkmark$ Impact Kami memiliki tujuan untuk menciptakan perbedaan yang positif kepada customer dan sesama.

$\checkmark$ Ownership Kami bertanggung jawab akan setiap perbuatan dan perkataan, serta memperlakukan Shirokuma seperti rumah kami sendiri.

$\checkmark$ Nurture Kami menyemangati satu sama lain untuk terus belajar dan berkembang.

Perkembangan teknologi yang terus berkembang pesat membuat kemudahan untuk para pelaku usaha dalam mengembangkan usaha khususnya dalam melakukan promosi. Kondisi ini lah yang dimanfaatkan dalam bidang promosi melalui teknologi ditambah lagi dengan keadaan sekarang yang tidak memungkinkan dalam melakukan kegiatan promosi secara offline. Hal tersebut juga dilakukan Shirokuma Cafe. Wawancara dilakukan secara online dan offline tatap muka dengan Ibu Victoria selaku Head Office Shirokuma Café dan Bapak Chandra selaku pegawai Shirokuma Café untuk mengetah ui data yang diperlukan untuk penelitian peneliti. alam melaksanakan strategi promosinya Shirokuma Cafe tidak mengimplementasikan seluruh bauran promosi seperti penjualan perorangan dan public relation yang di mana menurut $\mathrm{Ibu}$ Victoria hal ini kurang cocok dengan keadaan saat ini yang masih terjadi pandemic COVID19, selain itu juga membutuhkan anggaran yang tidak sedikit untuk melaksanakannya. Namun Shirokuma Cafe sangat mengutamakan bauran promosi mereka seperti periklanan, promosi penjualan, dan direct marketing dalam menjalankan strategi promosinya. Media yang mereka gunakan menurut Ibu Victoria dan Bapak Chandra adalah dalam melakukan kegiatan-kegiatan promosi tersebut Shirokuma Cafe memanfaatkan media internet berupa media sosial seperti Instagram.

- Periklanan

Shirokuma Cafe mengiklankan produk-produk mereka ke media sosial Instagram dan Facebook dengan menggunakan foto-foto produk milik mereka sebagai iklan dengan kualitas HD sehingga memungkinkan viewers untuk melihat produk secara detail. Setiap postingan mereka yang ada di Instagram selalu disertai dengan caption yang menarik dan tidak membosankan.

\section{- Promosi Penjualan}

Shirokuma Cafe selama masa pandemi sering mengadakan potongan harga dan menginformasikannya ke Instagram milik mereka. Salah satu nya adalah memberi potongan harga untuk produk kopi mereka 
bagi pelanggan yang sudah divaksin dengan menunjukkan kartu vaksin mereka.

- Direct Marketing

Dalam hal ini Shirokuma Cafe kerap kali melakukan pengiriman pesan dan Whattsapp blast untuk memberi informasi Shirokuma Cafe terkini kepada para member yang tercantum nomor teleponnya.

\section{Tringulasi sumber}

Dari hasil wawancara yang dilakukan oleh terhadap narasumber dalam penelitian dan observasi ini mendapatkan jawaban bahwa strategi promosi yang ada pada Shirokuma Cafe menjadi salah satu aspek penting untuk menarik pelanggan dan meningkatkan penjualan dimasa pandemi ini.

\section{Analisis Data dan Interpretasi Strategi Promosi Shirokuma Cafe di masa Pandemi}

Tujuan suatu perusahaan dalam melakukan kegiatan promosi adalah untuk memperkenalkan produk yang mereka miliki sehingga masyarakat mengetahui dan menjadi tertarik dengan produk milik perusahaan tersebut. Berikut ini strategi promosi atau bauran promosi yang dilakukan Shirokuma Cafe selama masa pandemi:

a) Periklanan (Advertising)

Periklanan adalah suatu bentuk promosi barang atapun jasa yang sifatnya tidak personal oleh sponsor yang diketahui. Periklanan mampu menjangkau konsumen lebih banyak dan mencakup wilayah yang luas. Dalam hal ini periklanan yang dilakukan Shirokuma Cafe selama masa pandemi adalah menggunakan media sosial berupa Instagram dalam mengiklankan dan menginformasikan produk milik mereka. Hal ini dilakukan untuk memungkinkan banyak konsumen untuk mengakses informasi dengan lebih mudah dan detail.

Dalam hal ini dapat dikatakan bahwa periklanan memiliki kontribusi dalam menarik minat pelanggan untuk melakukan pembelian, sehingga dapat diasumsikan periklanan hal yang penting dilakukan oleh sebuah perusahaan dalam meningkatkan penjualan. b) Penjualan Perorangan (Personal Selling)

Penjualan perorangan adalah interaksi langsung oleh pemasar dengan maksud menarik konsumen, membuat penjualan, serta membangun relasi dengan konsumen. Sayangnya dalam hal ini Shirokuma Cafe selama masa pandemi tidak melakukan penjualan perorangan dikarenakan keadaan tidak memungkinkan untuk melakukan penjualan perorangan.

c) Promosi Penjualan (Sales Promotion)

Promosi penjualan adalah insetif jangka pendek untuk mendorong keinginan konsumen untuk mencoba atau membeli suatu produk. Hal ini bertujuan untuk menarik perhatian konsumen, merangsang minat, dan meningkatkan penjualan suatu produk. Dalam hal ini Shirokuma Cafe selama masa pandemi melakukan romosi penjualan dengan memberikan potonganpotongan harga pada beberapa produk mereka dan menginformasikannya menggunakan media sosial Instagram. Salah satu promosi penjualan mereka adalah pada 17 Agustus Shirokuma Cafe memberi promosi berupa potongan harga untuk produk kopi mereka dengan menunjukkan kartu vaksin untuk para pelanggan yang sudah divaksin.

Promosi penjualan sangat efektif dalam menarik para pelanggan, seperti yang dikemukakan oleh (Liliyana, 2020) bahwa hal tersebut dikarenakan adanya faktor psikologis orang Indonesia sangat menyukai berbagai jenis promosi terutama potongan harga. Hal ini lah membuat kegiatan promosi penjualan terbilang efektif dalam menarik para pelanggan.

\section{d) Public Relation}

Public Relation yaitu sebuah promosi dengan membangun hubungan baik dengan berbagai publik, membangun image perusahaan yang baik dan menetralkan rumor atau opini negatif perusahaan akan mampu mendapaatkan kepercayaan yang baik dari publik. Sayangnya selama masa pandemi Shirokuma Cafe tidak melakukan kegiatan public relation, menurut mereka untuk melakukan public relation seperti 
Versi Online:

https://journal.ubm.ac.id/index.php/hospitality-pariwisata Doi: http://dx.doi.org/10.30813/jhp.v7i2.3024 Hasil Penelitian

mengadakan sponsorship membutuhkan budget yang tidak sedikit.

\section{e) Direct Marketing}

Direct Marketing adalah terlibat langsung dengan individu yang ditargetkan dengan cermat kepada konsumen untuk mendapatkan tanggapan langsung dan dapat membangun hubungan pelanggan dalam jangka panjang. Dalam hal ini Shirokuma Cafe melakukan direct marketing dengan cara memberi SMS Blast kepada para member yang tersimpan nomornya di database Shirokuma Cafe, elain itu juga Shirokuma Cafe mengkombinasikan direct marketing dengan digital marketing yaitu melakukan Whatsapp blast kepada para member.

Hasil penelitian menunjukkan bahwa kegiatan promosi yang dilakukan Shirokuma Cafe selama masa pandemi terfokus dengan memanfaatkan media sosial Instagram sebagai media utama untuk menarik para pelanggan dan meningkatkan penjualan. Kegiatan promosi yang dilakukan Shirokuma Cafe efektif dalam meningkatkan penjualan sehingga kerugian yang dialami Shirokuma Cafe tidak separah ketika awal PSBB berlangsung.

\section{SIMPULAN DAN SARAN}

\section{Simpulan}

Berdasarkan hasil penelitian, peneliti memperoleh kesimpulan dari penelitian yang berjudul "Strategi Promosi Shirokuma Cafe di Masa Pandemi". Peneliti mengambil kesimpulan sebagai berikut:

- Periklanan adalah suatu bentuk promosi barang atapun jasa yang sifatnya tidak personal oleh sponsor yang diketahui. Periklanan mampu menjangkau konsumen lebih banyak dan mencakup wilayah yang luas. Peneliti menarik kesimpulan bahwa periklanan yang dilakukan Shirokuma Cafe selama masa pandemi adalah menggunakan media sosial berupa Instagram dalam mengiklankan dan menginformasikan produk milik mereka. Penjualan perorangan adalah interaksi langsung
Jurnal Hospitality dan Pariwisata Vol.7 (No. 2): 103 - 109. Th. 2021 p-ISSN: 2442-5222 e-ISSN: 2655-8165

oleh pemasar dengan maksud menarik konsumen, membuat penjualan, serta membangun relasi dengan konsumen. Peneliti menarik kesimpulan dari hasil wawancara bahwa Shirokuma Cafe selama masa pandemi tidak melakukan penjualan perorangan dikarenakan keadaan tidak memungkinkan untuk melakukan penjualan perorangan.

- Promosi penjualan adalah insetif jangka pendek untuk mendorong keinginan konsumen untuk mencoba atau membeli suatu produk. Hal ini bertujuan untuk menarik perhatian konsumen, merangsang minat, dan meningkatkan penjualan suatu produk. Peneliti menarik kesimpulan bahwa alam hal ini Shirokuma Cafe selama masa pandemi melakukan promosi penjualan dengan memberikan potongan-potongan harga pada beberapa produk mereka serta menginformasikannya menggunakan media sosial Instagram.

- Public Relation yaitu sebuah promosidengan membangun hubungan baik dengan berbagai publik, membangun image perusahaan yang baik dan menetralkan rumor atau opini negatif perusahaan akan mampu mendapaatkan kepercayaan yang baik dari publik. Peneliti menarik kesimpulan dari hasil wawancara bahwa selama masa pandemi Shirokuma Cafe tidak melakukan kegiatan public relation, menurut mereka untuk melakukan public relation seperti mengadakan sponsorship membutuhkan budget yang tidak sedikit.

- Direct Marketing adalah terlibat langsung dengan individu yang ditargetkan dengan cermat kepada konsumen untuk mendapatkan tanggapan langsung dan dapat membangun hubungan pelanggan dalam jangka panjang. Peneliti menarik kesimpulan Shirokuma Cafe melakukan direct marketing dengan cara memberi SMS Blast kepada para member yang tersimpan nomornya di database Shirokuma Cafe, selain itu juga Shirokuma Cafe mengkombinasikan direct marketing dengan digital 
marketing yaitu melakukan Whatsapp blast kepada para member.
Kualitatif, dan R\&D) (21th ed.). Alfabeta.

\section{Saran}

Shirokuma Cafe berdasarkan dari hasil temuan yang didapat telah menerapkan 3 strategi promosi yang ada yaitu: periklanan, promosi penjualan, dan direct marketing dengan menggunakan media sosial Instagram serta Whatsapp. Shirokuma Cafe bisa melakukan periklanan dengan menggunakan brosur atau dengan menggunakan podcast untuk memperkenalkan Shirokuma Cafe ke masyarakat luas juga pada promosi penjualan Shirokuma Café dengan mengadakan cashback pada pembayaran melalui OVO di setiap gerai milik Shirokuma Cafe. Pada direct marketing Shirokuma Cafe bisa melakukan penyebaran informasi melalui email kepada para pelanggan, gunanya agar masyarakat makin mengetahui Shirokuma Café.

Saran untuk penelitian selanjutnya dapat melakukan penelitian lebih mendalam dari aspek marketing lain tidak hanya dari segi promosi yang dapat membantu beberapa restoran atau café dalam mempertahankan bisnis di masa pandemi.

\section{DAFTAR PUSTAKA}

Fitrah, M., \& Luthfiyah. (2017). Metodologi Penelitian: Penelitian Kualitatif, Tindakan Kelas, \& Studi Kasus (Ruslan \& M. M. Effendi (eds.)). CV Jejak.

Liliyana. (2020). Implementasi Bauran Promosi Pada Usaha Kuliner Restoran Bumbu Desa Ciledug Di Masa Pandemi COVID-19. Journal of Chemical Information and Modeling, 53(9), 1689-1699.

Sitorus, O. F., \& Utami, N. (2017). Strategi promosi pemasaran. In Fkip Uhamka. Fakultas Keguruan dan Ilmu Pendidikan Universitas Muhammadiyah Prof. Dr. HAMKA.

Sugiyono. (2015). Metodologi Penelitian Pendidikan (Pendekatan Kuantitatif, 